\title{
El género cinematográfico como elemento condicionante de la dimensionalidad del personaje del cine clásico de Hollywood: características de los personajes cinematográficos redondos y planos.
}

Film Genre as a Conditioning Element in the Dimensionality of the Film Character in the Classical Hollywood Cinema: Aspects of the Cinematographic Round and Flat Characters.

José Patricio Pérez Rufí

Universidad de Málaga

patricioperez@uma.es

http://dx.doi.org/10.12795/AdMIRA.2017.02.02

\section{Resumen}

Esta investigación tiene como objetivo principal el análisis de los protagonistas de una muestra de filmes producidos dentro de la práctica del cine clásico de Hollywood entre 1930 y 1960. Nuestra hipótesis es que el género cinematográfico condiciona la configuración del personaje hasta llegar a comprometer el volumen que adquirirá el personaje, a partir de la conjunción de una serie de factores que pretendemos identificar. Realizamos un análisis textual de una muestra de películas representativas del periodo clásico, a partir de un muestreo subjetivo por decisión razonada. Analizamos cincuenta personajes protagonistas y los clasificamos en las categorías clásicas de Forster como personajes redondos y personajes planos. Concluimos que la dimensionalidad del personaje cinematográfico se obtiene a través de la transmisión de una amplia cantidad de información. Así, el género fílmico condiciona en gran medida la construcción del sujeto cinematográfico.

Palabras clave: Narrativa fílmica; género cinematográfico; personaje cinematográfico; análisis fílmico; guion cinematográfico; cine clásico de Hollywood; estrellas de cine. 


\begin{abstract}
The main goal of this paper is to analyze the main character in a sample of films produced in the classical Hollywood cinema practice between 1930 and 1960. Our hypothesis is that the film genre influences the creation of the character to the point of compromising the dimensionality that the character could achieve, due to many factors that we pretend to identify. We make a textual analysis in an iconic classic films sample, from a subjective sample by reasoned decision. We analyze fifty main characters and we classify them in the classic categories by Forster as round characters and flat characters. We conclude that the dimensionality in the film character is the result of the transmission of a large number of information. Film genre determinates strongly the construction of the cinematographic agent.
\end{abstract}

Keywords: Film Narration; Film Genre; Cinematographic Character; Film Analysis; Screenplay; Classical Hollywood Cinema; Movie Stars. 


\section{Introducción.}

El cine producido en Hollywood entre 1930 y 1960, la que se ha considerado "edad dorada del cine", parece alejarse de las inquietudes de un mundo post-moderno que accede aún al espectáculo cinematográfico a través de los extraordinarios juegos fotográficos que la tecnología digital permite y de modos de recepción que pretenden implicar todavía más al espectador. A pesar de todo, desde un plano narrativo el cine de hoy no aporta tantas novedades como pudiera parecer y los avances formales $\mathrm{y}$ narrativos de este modelo de cine siguen vigentes hoy día desde la permanencia de lógicas y construcciones del relato universales, con independencia del formato.

La base de la existencia de un cine clásico estadounidense reposa sobre la argumentación enunciada por Bordwell, Staiger y Thompson (1997: XIV) de "sistema de práctica cinematográfica", como serie de normas estilísticas ampliamente aceptadas que confluyen con un sistema integral de producción, que a su vez sostiene dichas reglas. De esta forma, nos hallaríamos ante un sistema constante donde las normas formales y estilísticas se crean y toman forma dentro de un modo de producción. Así, como sistema de práctica cinematográfica, el cine clásico constituye "una tradición estética de una coherencia aceptable que mantiene la creación individual" (Bordwell, Staiger \& Thompson, 1997: 4).

A partir de este concepto podemos comprender la naturaleza dual del cine clásico: como contexto de producción acotado e identificable con un espacio y tiempo histórico precisos, así como un conjunto de rasgos estilísticos coherentes que responden a una gramática audiovisual común. En este caso, los condicionantes extracinematográficos o de producción explicarían las posibilidades formales $\mathrm{y}$ narrativas del producto hollywoodense clásico.

La existencia de un estilo clásico dentro del sistema de práctica cinematográfica en Hollywood entre 1917 y 1960 se erige como un concepto teórico definido y limitado cuya existencia habrá de constituir una premisa de indudable valor funcional en nuestra investigación. Bordwell, Staiger y Thompson (1997: 11) consideran la elección de 1960 como colofón del período clásico una opción arbitraria pero funcional de cara a la investigación.

Hemos de señalar que estas fechas sirven solamente como marco de referencia; es posible hallar filmes que sobrepasan en uno $u$ otro sentido estas fechas y que se 
corresponden a lo que entendemos por cine clásico. Por el contrario, también podemos encontrar películas que no pertenecen al modelo clásico dentro de estas fechas y del contexto de producción del studio system.

Nuestra investigación tiene como objetivo principal el análisis de los protagonistas de una muestra de títulos producidos dentro de la práctica del cine clásico de Hollywood entre 1930 y 1960, con objeto de identificar parámetros que pongan en relación la dimensionalidad del protagonista, esto es, su verosimilitud como simulacro de la persona, con el género cinematográfico en el que se inscribe su presencia. Partimos pues de la hipótesis de que el género cinematográfico condiciona la configuración del personaje como contexto modelizador de categorías de personajes, de tal forma que el género comprometerá el volumen que adquirirá el personaje, desde de la conjunción de una serie de factores que pretendemos identificar. Nuestra investigación, a través del estudio del personaje protagonista, intenta así comprender los mecanismos de configuración de una categoría narrativa que consideramos puede dotar de coherencia a la práctica cinematográfica clásica.

La observación de la construcción dramática del personaje como categoría narrativa primará un acercamiento a la producción cinematográfica de Hollywood en cuanto relato finalizado (no como algo que pudo ser), con una entidad autónoma a sus condiciones de realización. A juicio de Coursodon (1996: 228), durante este período, casi la totalidad de las películas producidas en Hollywood pertenecen con toda seguridad a un género concreto, entendido así desde su identificación con unas convenciones narrativas, temáticas y formales fácilmente reconocibles por el espectador, es decir, con un alto nivel de especialización. Este grado elevado de especialización supondría un valor nuevo con respecto al cine de los años 20.

Durante los años 30 y 40 se mantiene la vitalidad de los géneros, si bien a partir de los 50 comienza su agonía: los géneros, afirma Gubern (1996: 70), se hacen autoconscientes y tratan de desembarazarse de sus convenciones, cada vez más arcaicas. Los movimientos en los gustos y hábitos de los espectadores, así como la disolución del sistema de los estudios, correrán paralelos a la degradación de los géneros. Puede, por tanto, concluirse que la narrativa clásica cinematográfica de Hollywood se identifica con un cine de género. 
Apuntemos que, como recoge Altman (1999: 35), el término género no es "un término descriptivo cualquiera, sino un concepto de múltiples significados" que podría identificarse como un esquema que procede, programa y configura la producción de la industria, que estructura formalmente el filme, lo etiqueta y lo hace reconocible por los diferentes agentes que participan en las diversas fases del proceso de producción, distribución y comercialización del filme.

No resultará fácil establecer las características que le dan identidad a un género y lo diferencian del resto, tanto más desde el momento en que los filmes articulan y mezclan diferentes lenguajes y componentes y la propia creación de una clasificación de géneros estará sujeta, por fuerza, a la crítica.

\section{La dimensionalidad del personaje cinematográfico.}

La consideración de la dimensionalidad del personaje implica la concepción del mismo como simulacro de la persona, alejándonos, por tanto, del concepto de personaje como unidad de acción según lo aceptaban formalistas o estructuralistas (Pérez-Rufí, 2016: 550). Según Casetti y Di Chio (1998: 78), el análisis como persona supone "asumirlo como un individuo dotado de un perfil intelectual, emotivo y actitudinal, así como de una gama propia de comportamientos, reacciones, gestos, etc.", por lo que es interpretado como real. La esencia de esta visión se encuentra en la consideración del sujeto narrativo como simulación de un referente real.

Esta descripción del personaje contaría con el apoyo implícito de los autores de manuales de guión en cuanto a la construcción de los caracteres (Comparato, 1992; Field, 1995; Seger, 2000). El problema que frecuentemente conlleva es la confusión entre los planos de la ficción y la realidad, que llega, según Bobes (1990: 49), "a admitir como válido en uno de los planos lo que es verdadero sólo para el otro".

Aunque el estructuralismo en general no acepta un análisis del personaje como persona, el propio Greimas (1971: 264) sostiene la validez del análisis cualitativo para completar al actancial y Bal (1998: 156) admite que la posesión de rasgos permite una descripción psicológica o ideológica.

Aplicado a los casos del cine de Almodóvar y Williams, Durán (2017: 102) afirma que "el análisis como persona y como rol se plantea como un recurso para 
intentar conocer en profundidad la psicología de los personajes", idea que pueda aplicarse a nuestro caso desde el momento en que la dimensionalidad del personaje vendrá de la mano de la atención al volumen de la construcción de su psicología.

En su propuesta de análisis del personaje como persona, Casetti y Di Chio (1998: 178) crean tres grupos de categorías opuestas de carácter psicológico: 1) Personaje plano/personaje redondo; 2) Personaje lineal/personaje contrastado; 3) Personaje estático/personaje dinámico.

Casetti y Di Chio, en definitiva, diferencian tres matices de la tradicional evaluación en personajes redondos y personajes planos seguida por la crítica literaria anglosajona a partir de la publicación de Aspects of the novel de Forster en 1927. Los tipos de Forster, según Chatman (1990: 141), han resistido los cambios en el debate literario y han sido criticados por su falta de rigor y por su escaso ajuste a los criterios científicos. Sin embargo, los postulados de Forster siguen siendo objeto de controversia y continúan vigentes en gran parte de la metodología analítica del personaje. Su reinterpretación por Casetti y Di Chio o Chatman actualizan la evaluación del sujeto narrativo en estos conceptos.

Dentro de las categorías de análisis del personaje como persona propuestos por Casetti y Di Chio atenderemos en esta investigación únicamente a la consideración de la dimensionalidad en la construcción del personaje como persona en cuanto a la clásica categorización de personajes como planos o redondos.

El personaje redondo es complejo y variado (Casetti \& Di Chio, 1998: 178), multidimensional, con gran variedad de rasgos, abundantes en número y en calidad, lo que le asimilan a un sujeto con psicología propia y personalidad individual (García Jiménez, 1993: 304). Mientras que el personaje plano era menos recordado, el esférico, según Chatman (1990: 142), "puede inspirar una sensación más entrañable (...) Los recordamos como a personas de verdad".

Forster (1983: 79) indica que sólo los personajes redondos pueden desempeñar papeles trágicos, "suscitando en nosotros emociones que no sean humor $\mathrm{o}$ complacencia". Con todo, el elemento principal de valoración del personaje como redondo sería su capacidad para sorprender de una manera convincente, de tal modo que si nunca sorprende, es plano, y "si no convence, finge ser redondo pero es plano. Un personaje redondo trae consigo lo imprevisible de la vida", añade (Forster, 1983: 89). 
En este caso, Chatman (1990: 143) cree que el personaje funciona como una construcción abierta capaz de generar nuevas ideas. La diversidad y discrepancia de rasgos provoca nuestra especulación acerca de posibles acciones futuras. Mario de Onaindia (1996: 140) realiza una observación que nos será de utilidad: mientras que cada personaje plano tiene un espacio característico, el personaje redondo se relacionará con todos los espacios y todas las categorías de agentes de la acción.

El personaje redondo también se reconocería como aquel lleno de ambigüedad y dudas, inestable, complejo y contrastado. El origen de la contradicción que lo define se halla en la incompatibilidad de los objetivos que persigue y su posibilidad de elección entre distintas alternativas. La evaluación entre personaje redondos y planos se correspondería así con la distinción unamuniana, sostiene Villanueva (1989: 53), entre personajes rectilíneos (siempre uniformes) y agónicos (debatidos entre constantes alternativas).

Por otra parte, Forster (1983: 75) define el personaje plano como aquel construido en torno a una sola idea o cualidad. Así, la esencia del personaje puede resumirse en una sola frase, sin mayor existencia fuera de ella. Como ventaja señala la facilidad de su identificación, además de que no es necesario definir su desarrollo y permanecen inalterables a cualquier circunstancia.

Según García Jiménez (1993: 304), los personajes planos son "toscos, estáticos, pobres, enunciadores de discursos muy poco variados y de comportamiento muy predecible y repetitivo". Chatman (1990: 141) apunta a que como sólo hay un único rasgo o uno dominante, la conducta es bastante previsible. En cualquier caso, los rasgos que lo definen no son contradictorios y aportan uniformidad en la construcción del sujeto; los objetivos del personaje se encauzan en una misma dirección sin que quede lugar para la duda o la ambigüedad.

El personaje plano, y en ello coinciden tanto los autores que siguen a Forster como los que lo critican, se asocia al tipo o al estereotipo. Alonso de Santos (1998: 251252) afirma que un estereotipo se construye con pocos rasgos comunes de carácter tópico ("una especie de retrato robot de una persona") y que en el tipo predominan unos pocos rasgos elementales. El estereotipo actuaría según un esquema conocido con anterioridad y repetitivo. 
De la reflexión de Forster ha transcendido principalmente, a juicio de García Jiménez (1993: 304), la consideración del personaje redondo como una aportación de calidad al relato en términos de verosimilitud, al hacerlo más legible y creíble, y de mimesis ("resulta ser un trasunto más fiel de la vida").

Vale (1989: 83) aconseja al guionista "crear contraste, porque hace que la caracterización se vea más real". El creador, afirma Alonso de Santos (1998: 264), debe intentar introducir en cada sujeto elementos contradictorios, ya que sus dudas internas ocasionan el debate en la duda, su contradicción o su equivocación.

Linda Seger (2000: 40) toma como referencia la persona para recomendar la incorporación de la paradoja en la construcción del personaje: “Teniendo en cuenta la naturaleza humana, un personaje es algo más que un conjunto de incoherencias. Las personas son ilógicas e imprevisibles (...) A menudo las paradojas constituyen la base de la creación de un personaje único y fascinante".

Con respecto a la relación entre dimensionalidad y género, Dyer (2001: 141) afirma que "esperamos que cualquiera que interprete el personaje masculino principal de un western encaje con los amplios parámetros de la caracterización del cowboy", con lo cual determinados géneros del clásico invitarían a la introducción de personajes estereotipados. Crespo (2001: 57) indica que el género funciona como un mecanismo capaz de crear un marco de interpretación y un horizonte de expectativas en el espectador, "ya que condicionan fuertemente aspectos fundamentales de la película", incluyendo también a los personajes.

Partiríamos, por tanto, de unos presupuestos que ligan la identidad de los personajes a los géneros en que se inscriben. Este aspecto es el que trataremos de confirmar a partir del análisis que efectuaremos en este trabajo.

\begin{tabular}{|l|l|}
\hline Características del personaje plano & Características del personaje redondo \\
\hline 1) Es simple y unidimensional. & 1) Es complejo, variado y multidimensional. \\
2) Está construido en torno a una sola idea o cualidad. Asociado & 2) Posee una gran variedad de rasgos, abundando en número y \\
al estereotipo, su esencia se resume en una sola frase. & en calidad. Psicología propia y personalidad individual. \\
3) No sorprende o no convence. & 3) Sorprende de manera convincente y genera nuevas ideas. \\
4) No se le recuerda como una persona real. & 4) Es recordado como una persona real. \\
5) Se asocia a un espacio característico. & 5) Interviene en todos los espacios y se relaciona con todas las \\
6) Tiene un comportamiento predecible y repetitivo. Carácter & categorías de personajes. \\
teleológico. & 6) Permite la especulación acerca de las posibles acciones \\
7) Es uniforme y bien calibrado. & futuras del personaje. \\
\hline
\end{tabular}




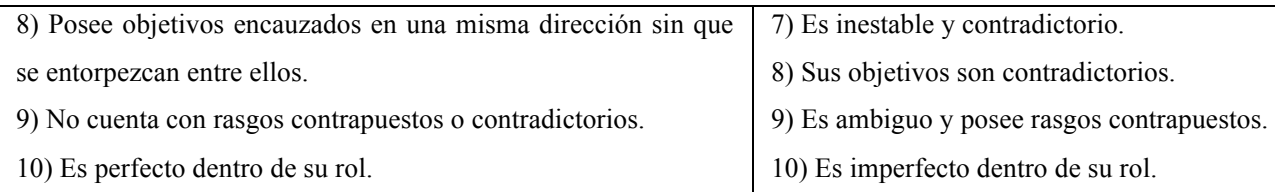

Tabla 1: Síntesis de características de personajes planos y personajes redondos.

Elaboración propia a partir de los autores citados.

\section{Metodología.}

Para realizar nuestra investigación partiremos del análisis de una muestra de películas representativas del período clásico. Hay que señalar que resulta compleja la selección de la muestra, aún más si tenemos en cuenta que ningún grupo de películas (mucho menos un único filme) es capaz de incorporar y condensar todas las características esenciales de un estilo. Aunque no es posible identificar la película "tipo", sí podemos reconocer una serie de películas representativas que responden al modelo de producción especializada que supone la práctica cinematográfica. Si bien podríamos ser acusados de hacer una historia en la "tradición de las obras maestras", según la denominación de Allen y Gomery (1995: 104), hemos de precisar que nuestra intención no es hacer una historia del cine, sino un análisis del modo en que se articulan las categorías narrativas en el discurso propio de la producción cinematográfica de un período histórico concreto.

Hemos empleado, por tanto, un muestreo "subjetivo por decisión razonada", en el que las unidades de la muestra no se eligen desde procedimientos estilísticos, sino "en función de algunas de sus características“ (Corbetta, 2007: 288-289).

Clasificamos los géneros desde la combinación de las propuestas de diversos autores. Así, Romaguera i Ramió (1999), a partir de las clasificaciones de Della Fornare, Hueso Montón y Gubern diferencia entre géneros específicos del cine (entre los que se encuentran el documental, el western, el policíaco, el musical, la comedia, el terrorfantástico y la ciencia ficción) y géneros híbridos del cine (con los géneros histórico, literario, aventuras, dramático, filosófico, colosalista y catrastrofista y erótico). Consideramos ésta una clasificación arriesgada por cuanto implicaría una necesaria investigación de los orígenes de cada género que difícilmente podría sostenerse.

Hemos preferido reducir el número de categorías y adaptarnos a la práctica cinematográfica objeto de nuestro estudio, el cine clásico de Hollywood, razón por la 
cual consideramos que determinados géneros no tendrían apenas cabida en una muestra representativa. Consideraremos los siguientes géneros: melodrama, cine negro, comedia, western, aventuras y musical. Esta simplificación a seis grandes géneros es por fuerza discutible, como lo pueden ser también categorizaciones más extensas procedentes de los estudios que hemos tomado como referencia (Selbo, 2015; Altman, 1999; Romaguera i Ramió, 1999).

La muestra se concreta en cincuenta títulos repartidos en seis géneros de la siguiente manera: catorce son melodramas, once pertenecen al cine negro, diez son comedias, seis obras se inscriben en el western y otras seis en el cine de aventuras, además de tres musicales. En esta selección se han conjugado títulos de los directoresautores más representativos del cine de los estudios y dentro del modelo de producción clásica, aunque hemos evitados casos con una concepción muy personal de la cinematografía que se alejan del modelo clásico, como Welles o Hitchcock.

Con objeto de limitar aún más la muestra, seleccionamos de cada filme un solo personaje para su análisis, aquel que identificamos en una posición jerárquica superior o con una mayor focalización en el relato, esto es, el protagonista, incluso si su rol moral no coincidiera con el del protagonista (o héroe) y pudiéramos entenderlo como antagonista, como recogemos en la tabla 2.

Los títulos seleccionados para el análisis son los siguientes:

\begin{tabular}{|l|l|l|}
\hline Melodrama & Personaje analizado & Intérprete \\
\hline Película & Mademoiselle Amy Jolly & Marlene Dietrich \\
\hline Marruecos (Morocco, Josef Von Sternberg, 1930) & Marie Kolverer / X27 & Marlene Dietrich \\
\hline Fatalidad (Dishonored, Josef Von Sternberg, 1931) & Marlene Dietrich \\
\hline $\begin{array}{l}\text { El expreso de Shanghai (Shanghai Express, Josef Von Sternberg, } \\
1932)\end{array}$ & Shanghai Lily & \\
\hline $\begin{array}{l}\text { Lo que el viento se llevó (Gone with the Wind, Victor Fleming, } \\
1939)\end{array}$ & Scarlett O'Hara & Vivien Leigh \\
\hline La carta (The Letter, William Wyler, 1940) & & \\
\hline La loba (The Little Foxes, William Wyler, 1941) & Leslie Crosbie & Bette Davis \\
\hline La señora Miniver (Mrs. Miniver, William Wyler, 1942) & Regina Giddens & Bette Davis \\
\hline Casablanca (Michael Curtiz, 1943) & Mrs. Miniver & Greer Garson \\
\hline La heredera (The Heiress, William Wyler, 1949) & Rick Blaine & Humphrey Bogart \\
\hline $\begin{array}{l}\text { Eva al desnudo (All About Eve, Joseph L. Mankiewicz, 1950) } \\
\text { La condesa descalza (The Barefoot Contessa, Joseph L. } \\
\text { Mankiewicz, 1954) }\end{array}$ & Matherine Sloper & Olivia de Havilland \\
\hline $\begin{array}{l}\text { Escrito en el viento (Written on the Wind, Douglas Sirk, 1956) } \\
\text { De repente, el último verano (Suddenly, Last Summer, Joseph L. }\end{array}$ & Catherine Holly & Bette Davis \\
\hline
\end{tabular}




\begin{tabular}{|c|c|c|}
\hline \multicolumn{3}{|l|}{ Mankiewicz, 1959) } \\
\hline Imitación a la vida (Imitation of Life, Douglas Sirkm 1959) & Lora Meredith & Lana Turner \\
\hline \multicolumn{3}{|l|}{ Cine negro } \\
\hline Película & Personaje analizado & Intérprete \\
\hline Hampa dorada (Little Caesar, Mervyn Le Roy, 1930) & Little Caesar/Rico & Edward G. Robinson \\
\hline El halcón maltés (The Maltese Falcon, John Huston, 1941) & Samuel Spade & Humphrey Bogart \\
\hline Perdición (Double Indemnity, Billy Wilder, 1944) & Walter Neff & Fred MacMurray \\
\hline $\begin{array}{l}\text { La mujer del cuadro (The Woman in the Window, Fritz Lang, } \\
\text { 1944) }\end{array}$ & Professor Richard Wanley & Edward G. Robinson \\
\hline Laura (Otto Preminger, 1944) & Laura Hunt & Gene Tierney \\
\hline Tener y no tener (To Have and Have Not, Howard Hawks, 1944) & Harry Morgan & Humphrey Bogart \\
\hline Gilda (Charles Vidor, 1946) & Johnny Farrell & Glenn Ford \\
\hline Perversidad (Scarlet Street, Fritz Lang, 1946) & Christopher Cross & Edward G. Robinson \\
\hline Cayo Largo (Key Largo, John Huston, 1948) & Frank McCloud & Humphrey Bogart \\
\hline Los sobornados (The Big Heat, Fritz Lang, 1953) & Dave Bannion & Glenn Ford \\
\hline Deseos humanos (Human Desire, Fritz Lang, 1954) & Jeff Warren & Glenn Ford \\
\hline \multicolumn{3}{|l|}{ Comedia } \\
\hline Película & Personaje analizado & Intérprete \\
\hline Sopa de ganso (Duck Soup, Leo MacCarey, 1933) & Rufus T. Firefly & Groucho Marx \\
\hline Sucedió una noche (It Happened One Night, Frank Capra, 1934) & Ellie & Claudette Colbert \\
\hline Una noche en la ópera (A Night at the Opera, Sam Wood, 1935) & Otis B. Driftwood & Groucho Marx \\
\hline Tiempos modernos (Modern Times, Charles Chaplin, 1936) & Un empleado de la fábrica & Charles Chaplin \\
\hline La fiera de mi niña (Bringing Up Baby, Howard Hawks, 1938) & Susan & Cary Grant \\
\hline $\begin{array}{l}\text { El bazar de las sorpresas (The Shop Around the Corner, Ernst } \\
\text { Lubitsch, 1940) }\end{array}$ & Alfred Kralik & James Stewart \\
\hline $\begin{array}{l}\text { Historias de Filadelfia (The Philadelphia Story, George Cukor, } \\
\text { 1940) }\end{array}$ & Tracy Lord & Katherine Hepburn \\
\hline Bola de fuego (Ball of Fire, Howard Hawks, 1941) & Bertram Potts & Gary Cooper \\
\hline Me siento rejuvenecer (Monkey Business, Howard Hawks, 1952) & Barnaby Fulton & Cary Grant \\
\hline El apartamento (The Apartment, Billy Wilder, 1960) & C.C. Baxter & Jack Lemmon \\
\hline \multicolumn{3}{|l|}{ Western } \\
\hline Película & Personaje analizado & Intérprete \\
\hline La diligencia (Stagecoach, John Ford, 1939) & Ringo Kid & John Wayne \\
\hline Pasión de los fuertes (My Darling Clementine, John Ford, 1946) & Wyatt Earp & Henry Fonda \\
\hline Río Rojo (Red River, Howard Hawks, 1948) & Thomas Dunson & John Wayne \\
\hline Winchester 73 (Anthony Mann, 1950) & Lin McAdam & James Stewart \\
\hline $\begin{array}{l}\text { El hombre de Laramie (The Man from Laramie, Anthony Mann, } \\
\text { 1955) }\end{array}$ & Will Lockhart & James Stewart \\
\hline Centauros del desierto (The Searchers, John Ford, 1956) & Ethan Edwards & John Wayne \\
\hline \multicolumn{3}{|l|}{ Aventuras } \\
\hline Película & Personaje analizado & Intérprete \\
\hline Rebelión a bordo (Munity on the Bounty, Frank Lloyd, 1935) & Christian & Clark Gable \\
\hline $\begin{array}{l}\text { El tesoro de Sierra Madre (The Treasure of Sierra Madre, John } \\
\text { Huston, 1948) }\end{array}$ & Dobbs & Humphrey Bogart \\
\hline
\end{tabular}




\begin{tabular}{|l|l|l|}
\hline La reina de Africa (The African Queen, John Huston, 1951) & Rose Sayer & Katherine Hepburn \\
\hline Moby Dick (John Huston, 1956) & Capitán Ahab & Gregory Peck, \\
\hline $\begin{array}{l}\text { Los diez mandamientos (The Ten Commandments, Cecil B. } \\
\text { DeMille, 1956) }\end{array}$ & Moisés & Charlton Heston \\
\hline Ben-Hur (William Wyler, 1959) & Judah Ben-Hur & Charlton Heston \\
\hline Musical & Personaje analizado & Intérprete \\
\hline Película & Gabey & Gene Kelly \\
\hline $\begin{array}{l}\text { Un día en Nueva York (On the Town, Stanley Donen y Gene } \\
\text { Kelly, 1949) }\end{array}$ & \\
\hline $\begin{array}{l}\text { Un americano en París (An American in Paris, Vicente Minnelli, } \\
\text { 1951) }\end{array}$ & Jerry Mulligan & Gene Kelly \\
\hline $\begin{array}{l}\text { Cantando bajo la lluvia (Singin'in the Rain, Stanley Donen y } \\
\text { Gene Kelly, 1952) }\end{array}$ & Don Lockwood & Gene Kelly \\
\hline
\end{tabular}

Tabla 2: Muestra de títulos y de personajes analizados.

Elaboración propia.

Con objeto de lograr los objetivos propuestos e identificar la influencia de los géneros cinematográficos del cine clásico en la configuración de los protagonistas, aplicaremos sobre la muestra de filmes un análisis textual según lo entienden Casetti y Di Chio (1991: 17), esto es, descompondremos las piezas presentes en la muestra y las recompondremos para así descubrir sus principios de construcción y su funcionamiento. Aplicaremos los criterios recogidos en la tabla 1 para clasificar a los personajes como planos o redondos y atenderemos a la construcción de cada uno de ellos desde la propuesta metodológica de análisis del personaje como persona de Casetti y Di Chio para llegar a conclusiones.

\section{Análisis y discusión de resultados.}

La distribución de personajes planos y redondos por géneros descubre una preponderancia de los redondos en el melodrama, a causa de la focalización primaria que requiere la presentación y descripción de los individuos: la base emocional del conflicto que viven los actantes del melodrama justifica y necesita de su multidimensionalidad. Los tipos planos, sin embargo, abundarán en el western y la comedia. Con objeto de determinar los rasgos que comparten los tipos incluidos en uno u otro grupo y descubrir sus lógicas de construcción analizaremos por separado cada categoría. 


\subsection{Los personajes redondos.}

4.1.1 Melodrama.

El melodrama invita a una focalización prioritaria del personaje como eje de los conflictos. Es en el melodrama donde el director Joseph L. Mankiewicz describe a algunos de los personajes más desarrollados y sorprendentes del cine clásico, como las protagonistas de Eva al desnudo, La condesa descalza y De repente, el último verano. Con una estructura no lineal, cambios en la focalización de la historia y actualización de narradores, las obras señaladas de Mankiewicz configuran un contexto en el que la transmisión de información acerca de los sujetos principales de la acción se convierte en una de las prioridades del discurso. Su descripción no se limita a la exhibición de los personajes en momentos privados en los que se expresan en libertad; la aportación de datos acerca de los protagonistas por los narradores y otros actantes con los que interactúan permite contrastarlos y observarlos con una distancia crítica.

Bette Davis es Margo Channing en Eva al desnudo, una diva del teatro construida desde elementos procedentes de una figura estereotipada que supera. Caprichosa, frívola, egocéntrica o despistada, pudiendo ser cruel y despiadada en un tono caricaturesco, desde el primer momento se hace verosímil y humana, gracias a la variedad de sus rasgos. Así, no sólo es la mujer celosa de su éxito y ambiciosa, personaje que interpreta conscientemente teniendo un público ante sí, sino que también es la víctima, engañada, despreciada y decadente que, al tanto de su situación y de su imagen pública, lo asume con ironía y cinismo. Margo se convierte en una construcción psicológica creíble y realista que encuentra una motivación psicológica, en ocasiones oscura e irracional, para cada gesto o frase. Ésta adquiere una personalidad propia a través de la cual resulta convincente y sorprendente a causa de su imprevisible comportamiento. La conjunción de elementos que la convierten en víctima al tiempo que culpable la componen como un sujeto narrativo extremadamente complejo.

La condesa descalza plantea de nuevo un juego de narradores y una ordenación cronológica no lineal que gira en torno a la historia de María Vargas (Ava Gardner), bailaora española que pasa a ser estrella de cine y condesa con destino trágico. Aun contando con narradores (autodiegéticos) y una focalización continua, la protagonista del filme se erige como una mujer misteriosa y algo opaca en cuanto a la expresión de sus inquietudes y carencias. Al igual que Margo, María Vargas conoce el éxito en el 
terreno profesional, sin llegar a los extremos de ambición y egocentrismo de la primera. $\mathrm{Su}$ necesidad de afecto la transforma en un ser mutilado emocionalmente, infeliz e insatisfecha pese a la supuesta consecución de todas sus metas, plena en complejidad y dimensión por lo que a su construcción dramática se refiere. La crisis que vive la conduce a un comportamiento contradictorio que la humaniza: en la última parte de la historia demuestra amar al conde Vincenzo (Rossano Brazzi) al tiempo que necesita de amantes. De esta forma, se aleja del estereotipo de heroína romántica de Hollywood, sin llegar a identificarse con la figura de la femme fatale debido a su dulzura.

Los objetivos de María son contradictorios debido a la motivación que subyace en ellos: antes que por una firme voluntad de actuación en una dirección, el personaje se mueve por su reacción contra otros sujetos que pretenden dominarla. Es por ello que decide ir a Hollywood (en contra de la opinión de su madre), seguir a Bravano (resistiéndose al productor Clarke) y posteriormente al conde (al oponerse a Bravano). La consecuencia del debate de la protagonista entre las alternativas posibles es el incremento de su inestabilidad, lo que redunda en un carácter complejo.

El tercero de los personajes de obras de Mankiewicz que evaluamos como redondo es Catherine Holly (Elizabeth Taylor) en De repente, el último verano. La aparente enajenación mental que afecta a Catherine, motivada por la traumática muerte de Sebastian, justifica su retrato como un personaje extremadamente complejo, ambiguo, inestable, desequilibrado e irracional. Con todo, el resultado es compacto y coherente con la desesperada situación que vive. Conociendo el destino que su tía (Katherine Hepburn) ha planificado para ella, su anulación como persona mediante la lobotomía, Cathy se debate entre la lucha por la supervivencia y la superación del trauma por la muerte de Sebastian y una tendencia a la autodestrucción, con lo que sus objetivos y, consecuentemente, su actuación serán paradójicos y confusos pero congruentes, prueba de la dimensión (humana y realista) del personaje. En definitiva, el personaje aspira a decidir por sí misma la dirección de sus actos.

Del mismo modo que Margo en Eva al desnudo y María en La condesa descalza eran conscientes del rol social que desempeñaban y se burlaban del mismo al interpretar el papel que se le suponía, Cathy se define como "loca" y pretende hacerlo creer, actuando de forma violenta contra el personal que la atiende en el psiquiátrico. Esta autoconsciencia de sus limitaciones y problemas psíquicos convencen de la cordura del 
personaje ante el espectador. La dimensionalidad del personaje la muestra como víctima de las maquinaciones de su tía, de modo que consigue activar la identificación del espectador.

Un rasgo común a los tipos redondos del melodrama es su ambigüedad moral. En un plano impreciso de rectitud, los sujetos no se identifican con el héroe de nobleza intachable ni con el antagonista siniestro, sino que divagan por caminos intermedios, más grises que oscuros, aunque siempre justificados, con lo cual el espectador compartirá sus criterios de actuación.

Sería el caso de Rick (Humphrey Bogart) en Casablanca, inicialmente observador pasivo desde una posición privilegiada de los abusos del enemigo nazi e insensible en apariencia al dolor ajeno. El desarrollo de la historia y la aportación de información a través del flashback de París, que lo muestra en un registro totalmente diferente, permite comprender el sufrimiento del personaje, aún herido por la ruptura amorosa con Ilsa (Ingrid Bergman).

Rick resulta ser un personaje contradictorio y complejo, en crisis, cuya falta de compromiso inicial incide en su ambigüedad moral, pero no impide que desprenda una imagen de gran entereza e integridad. Este contraste y la variedad de rasgos que lo definen lo alejan de cualquier estereotipo y hacen de él un sujeto redondo, multidimensional, imprevisible en su comportamiento e imperfecto dentro de su rol. Al mismo tiempo, el final del filme nos permite la especulación acerca de sus posibles acciones futuras, ya en la lucha contra el enemigo nazi.

En La carta, Bette Davis da vida a Leslie Crosbie, un personaje con diferentes caras, sospechosa de asesinato, artificiosa y cruel, pero al mismo tiempo martirizada, amable y dulce: el espectador no dispone de suficientes elementos de juicios como para calificarla en un sentido positivo o negativo. Su caracterización se llena de rasgos variados que le imprimen un carácter diverso y verosímil. Es así como puede entenderse como la amante apasionada, pero también como la tejedora laboriosa.

La responsabilidad del misterio que la rodea procede en gran parte de determinadas decisiones de la realización. Wyler hace hablar a la colona anglosajona de espaldas a la cámara y a los demás caracteres o evitando la mirada de aquellos. Consigue con ello proyectar una sombra de duda ante sus afirmaciones y ante la actitud con la que se declara inocente del crimen que da origen al conflicto. Junto a Wyler, Bette Davis 
volvía a componer otro personaje oscuro al tiempo que redondo y motivado en su actuación de forma realista en La loba.

Parten en el melodrama de un estereotipo progresivamente dimensionalizado algunos de los personajes principales femeninos considerados más célebres en la historia del cine, como son las protagonistas de Lo que el viento se llevó, La heredera o las interpretadas por Marlene Dietrich en las películas dirigidas por Josef Von Sternberg.

Así, Lo que el viento se llevó describe la evolución de Scarlett (Vivien Leigh), una joven caprichosa e infantil en el inicio del filme que se desplaza a la madurez final a partir de la lucha por la supervivencia y de las tragedias que afectan a su estabilidad vital. Muy cercana al estereotipo de burguesa sureña, pronto revelará indicios de poseer una personalidad contundente que la diferencia de sus hermanas y de los otros caracteres adolescentes, actuando de forma imprevisible y contradictoria. Es de este modo como se explica su repentina boda con el señor Hamilton, motivada por sus sentimientos de despecho y celos.

El resto de la historia articulará de modo paralelo su intensa actuación por la supervivencia en adversas circunstancias y su acción en el terreno sentimental en torno a otro personaje, Ashley (Leslie Howard), quien no le corresponde. Scarlett tiene como objetivo conseguir ser amada por Ashley, si bien en ocasiones reaccionará en su contra y parecerá proponerse metas opuestas. La contradicción de metas y de actitudes provocará una impresión de inestabilidad y verosimilitud en el personaje, redondo y contrastado, por lo tanto. Scarlett puede ser definida con adjetivos como egoísta, egocéntrica, caprichosa, infantil y cruel en ocasiones, pero también es de una desgarradora humanidad y una defensora de los valores en los que cree.

Otro estereotipo que gana en complejidad a través de su evolución en la historia es el interpretado por Olivia de Havilland (como Catherine Sloper) en la obra de Wyler La heredera. Durante la primera parte del filme, Catherine es una solterona ingenua, tímida, hogareña y aficionada al bordado que no ha conocido el amor y cree en las buenas intenciones de su pretendiente (Montgomery Clift). Su propio padre la define como "una criatura mediocre e indefensa, sin la menor seguridad en sí misma" y con una única virtud: su dinero.

El origen de la profundidad psicológica del personaje se encuentra en las relaciones con su padre. Éste someterá a la hija a una presión continua al compararla, 
siempre en un sentido despectivo, con su madre muerta, idealizada a lo largo de los años por el viudo.

Durante la segunda parte, "la heredera" conocerá el desengaño amoroso al saberse objeto de deseo únicamente por sus bienes materiales. Engañada y humillada, abandona su rol de joven humilde y apocada para presentar una faceta mucho más severa y perversa, incapaz de perdonar. Su venganza culmina con el desprecio al pretendiente que le engañó, al que creó falsas esperanzas de correspondencia amorosa tras su regreso.

Tenemos pues a un personaje con múltiples rasgos, un temperamento propio y una personalidad individual, sorprendente en su actuación final. La consecuencia es el abandono del modelo estereotipado de construcción dramática inicial para su transformación en un sujeto destacado por su riqueza psicológica.

Dentro de los personajes redondos del melodrama comentaremos brevemente en último lugar aquellos interpretados por Marlene Dietrich en los filmes dirigidos por Josef Von Sternberg analizados (Fatalidad, Marruecos y El expreso de Shangai). Sus tres protagonistas compartirán numerosos elementos en común. El más evidente es un punto de partida como mujeres fatales, estereotipo consolidado y referente constante en los tres filmes. Posteriormente, las heroínas demostrarán su complejidad a través de las contradicciones que parecen guiar su actuación. Así, Currie (1976: 77) afirma que las películas de Sternberg tienen una profundidad psicológica previa al descubrimiento de Freud por Hollywood en los 40, al sondear "hasta los más recónditos niveles la experiencia psíquica".

\subsubsection{Cine negro.}

En el cine negro el peso de estereotipos y de constantes de géneros impedirá en muchas ocasiones la adquisición de una entidad redonda por parte de sus protagonistas. Aunque hallemos sujetos oscuros insertos en el mundo criminal, estos simpatizan con el espectador y no desempeñan un rol antagonista debido a su integridad moral y nobleza. Entre otras propiedades, se definen por una ambigüedad moral que le hará debatirse entre distintas alternativas. La controversia interna le crea duda e inestabilidad, lo que repercute en la complejidad de la construcción dramática, en definitiva.

Edward G. Robinson ha encarnado algunos de los personajes redondos más interesantes del cine negro, género al que aparece irremisiblemente asociado. En Hampa 
dorada da vida a Cesare Bandello, gánster en Nueva York de procedencia italiana. Cesare se constituye como un sujeto apático, inestable, peligroso, vulgar, vanidoso, egoísta y pretencioso que, pese a todo, resulta atractivo gracias a su contundencia, su seguridad y la firme voluntad de conseguir sus objetivos valiéndose de cualquier medio, representando así a un héroe marginal con unos principios morales opuestos a la sociedad. El contrapunto a su carácter sociópata, gracias al cual adquiere mayor dimensión y variedad, puede advertirse en la relación con su amigo Jou (Douglas Fairbanks), al que no tolera que lo abandone por una mujer.

Aún más complejo y multidimensional es el protagonista interpretado por Robinson en la obra de Lang Perversidad: Cristopher Cross resulta un simulacro de la persona real verosímil. Ello se debe a la multitud de rasgos que lo componen, expuestos en las distintas escenas del filme. Así, éste puede ser observado desde su dimensión social y pública (en la celebración de la primera secuencia), en su trabajo en un banco o en la intimidad del hogar. Es en este último espacio donde el personaje se abrirá plenamente al espectador y donde se observará la soledad y miseria que habitan en su existencia. Maltratado psicológicamente y despreciado por su abusadora esposa, Cross sólo encontrará una salida a su rutina en la pintura.

Desde este contexto vital podrá explicarse la necesidad de evasión del empleado de banca y la ilusión e ingenuidad con que acoge su relación con la farsante Kitty, que le conducirá a la autodestrucción. A raíz de su encuentro con Kitty, Cross abandona la linealidad y convencionalismo de su rutina para delinquir y dirigirse hacia metas opuestas a su forma de vida, aspectos que terminan de redondearlo como personaje de contrastada construcción. Al igual que en Hampa dorada, la conducta subversiva del protagonista de Perversidad es penada, no con la muerte como en la anterior, sino con la pérdida del juicio y el acoso de voces fantasmales.

El sujeto principal de la acción en Perdición es Walter Neff (Fred McMurry), que comparte con los tipos de Robinson en La mujer del cuadro o Perversidad el hecho de ser una persona ajena al mundo criminal que, con el encuentro con una mujer fatal como detonante, se verá implicado una actuación homicida. Aquí, Neff es culpable del atentado contra el marido del personaje representado por Barbara Stanwyck, con un móvil económico y sexual, al tiempo que víctima de las maquinaciones articuladas por ella que escapan a su control. Éste adquiere asimismo dimensión a través de su 
confesión, moribundo y ante una grabadora (actualizando la figura del narrador autodiegético), siendo de tal modo las incertidumbres y temores los que hacen de él un sujeto contrastado y redondo.

En el cine negro, la mujer suele desempeñar un papel secundario, subordinado a la función del héroe, y muy relacionado en todo momento con el estereotipo de la mujer fatal, ambiciosa, vulgar, seductora y destructiva. Sin embargo, podemos encontrar algunos ejemplos de mujeres en papeles principales de cierta complejidad que se alejan del citado rol.

En Laura el efecto de ambigüedad moral que rodea a la protagonista (encarnada por Gene Tierney) se consigue a través de la comunicación velada de datos acerca de la vida de la "víctima" del asesinato mediante una articulación no lineal del filme. La focalización de la historia y la descripción del personaje a través de otros impiden su conocimiento directo. Una vez que Laura entra en escena aumenta el misterio a su alrededor, ahora como sospechosa del asesinato de la mujer hallada muerta. La ocultación intencionada de su actuación y sus confusas coartadas le restan credibilidad a sus palabras al tiempo que logran añadirle mayor contraste.

\subsubsection{Comedia.}

En cuanto a la comedia, la presencia tan escasa de tipos complejos puede explicarse por la índole secundaria que su construcción psicológica puede jugar en la narración. La prioridad es la creación de situaciones cómicas y diálogos humorísticos, a lo que puede contribuir en ocasiones la presencia de tipos cercanos al estereotipo.

Aquellos identificados como redondos lo son en gran medida debido al relieve que adquiere su vida emocional. Ello lo acercará al melodrama, género más propicio a la descripción de personajes por encima de la exhibición de la acción. Entre estos sujetos puede señalarse a Tracy Lord, interpretado por Katherine Hepburn en Historias de Filadelfia.

En un principio, Tracy es presentada como una "diosa de cobre", idealizada, perfecta, inaccesible y, según el personaje de James Stewart, "la típica mujer americana joven y rica", sin equivalente en otro país. Es de esta forma mostrada como arquetipo propio de la comedia americana de teléfonos blancos. El personaje, no obstante, manifiesta una complejidad insólita en el género a partir del momento en que el 
desarrollo del relato permite su exhibición directa sin la mediación de otros caracteres: su indecisión y la necesidad de definición de su personalidad y de preparación para el auténtico amor conllevan la variedad en su caracterización. Su capacidad para actuar de modo imprevisto y contradictorio, acorde con todo a su inseguridad, matiza y añade volumen a un tipo similar representado por la misma actriz en La fiera de mi niña. Es por ello que es capaz de sorprender y de resultar verosímil como simulacro de la persona real.

Jack Lemmon compone en El apartamento otro sujeto redondo. Aunque algo caricaturesco, su vinculación con otros personajes previamente conocidos es escasa. Éste posee una psicología propia, resultando convincente, sorprende por su comportamiento espontáneo y azaroso y se relaciona con todos los sujetos, mostrando un trato diferenciado con cada uno de ellos. Con objeto de permitir un acercamiento más directo, Woody se identifica en el discurso con la figura del narrador autodiegético, a través del cual se presenta y justifica su actuación.

Los objetivos de Woody son contradictorios: por una parte, pretende ascender dentro de su empresa; por otra, ansía conquistar la independencia y la libertad derivadas de la plena disposición de su vivienda. La discrepancia entre estas dos opciones origina un conflicto de donde surge el contraste. Esta incompatibilidad de metas lo convierten, de modo similar a como lo hacían otros sujetos narrativos redondos, en culpable y víctima de su situación. Woody puede ser juzgado responsable de la miseria que invade su vida debido en última instancia a su ambición profesional. Simultáneamente es víctima de la actuación de sus superiores: será este aspecto el que prime en la historia.

Historias de Filadelfia y El apartamento suponen dos formas distintas de concebir la comedia. Entre ambas median veinte años y una industria cultural absolutamente dispar. Si la primera es por completo representativa de la comedia clásica de Hollywood, El apartamento plantea nuevos temas y enfoques más modernos.

\subsubsection{Western.}

La razón de la escasez de protagonistas complejos en el western clásico se halla posiblemente en la repetición esquemática que implica el género, no ya sólo en aspectos argumentales, sino también en la construcción de tipos: son habituales los modelos heroicos con un escaso fondo psicológico. 
Discrepan de estos sujetos vagamente trazados los caracteres principales interpretados por John Wayne en Río Rojo y Centauros del desierto, ambos de gran ambigüedad moral, inestables y pragmáticos en su actuación. En la primera, Tom Dunson es un vaquero obligado a emigrar que evoluciona hacia la obsesión y la locura. El ganadero oscila entre el odio al hijo adoptado, del que prometió vengarse al ser abandonado, y su necesidad de descendencia y afecto a través de aquel.

El caso es similar en Centauros del desierto, donde Ethan habrá de buscar y rescatar a su única descendiente, su sobrina Debbie. Una vez hallada, y descubierta su conversión en un miembro más de una tribu india, no reconoce su parentesco. Este comportamiento se justifica en las informaciones previas que caracterizaron al sujeto (como el rechazo a la raza india de modo exacerbado), si bien resulta inesperado porque se opone a la meta principal que unifica la narración. Aunque sorprendente, la actuación de Ethan es coherente con la descripción del complejo temperamento del aventurero.

Por lo que se refiere a la confluencia de rasgos variados, en Ethan podemos apuntar su valentía, inteligencia, constancia y habilidad, pero también su crueldad, apatía, racismo y violencia. Es desde esta composición que puede explicarse su conducta heroica, al rescate de un ser indefenso, al tiempo que su perversa actitud frente al enemigo indio.

El western constituye un género que, a causa de su agotamiento temático y su adaptación a la exposición camuflada de problemas contemporáneos, evolucionará más velozmente que el resto. El western clásico (del que Río Rojo es representante pese a su complejidad psicológica) adquiere en los años 50 mayor profundidad en el planteamiento de temas en el llamado western psicológico. La decadencia vendrá con el western crepuscular, en el cual las coordenadas propias del género constituirán una excusa para desarrollar temáticas más arriesgadas y personajes más conflictivos.

\subsubsection{Aventuras.}

En el género de aventuras encontramos personajes redondos en varios de los filmes analizados dirigidos por John Huston, como Moby Dick, El tesoro de Sierra Madre y La reina de África. En Moby Dick, Gregory Peck, como el capitán Ahab, compone un sujeto aparentemente plano, frío, despiadado y obsesionado con la caza 
irracional de una ballena asesina. A través de su discurso se aprecia su crisis existencial y la paradoja que guía su actuación.

Obstinado y vengativo, Ahab es consciente de su enajenación. Se siente viejo, como si hubiese vivido siglos y notara el peso de esa soledad. Al tiempo, se pregunta por el sentido de la fuerza que le obliga a alejarse de sus seres queridos y mantener una lucha que considera absurda, la persecución de un monstruo que en su sano juicio no se atrevería a soñar. Ahab se debate entre la necesidad de vivir en paz y la de conseguir su objetivo, de lo que resulta un personaje contradictorio, ambiguo y redondo, por tanto.

El tesoro de Sierra Madre presenta a Alfred Dobbs (Humphrey Bogart) como un desempleado desesperado en la búsqueda de un tesoro que, al igual que el anterior, termina por trastornarlo. Los mecanismos psicológicos que le llevan a la autodestrucción, primero moral y después vital, son complejos y vienen a demostrar su dimensionalidad. Es necesario, con todo, apuntar la importancia que en la historia posee la temática a la que se subordina la configuración de personajes: la ambición desmedida conduce a los hombres a su perdición.

El tercero de los filmes de Huston reseñados, La reina de África, enfrenta dos caracteres algo esquemáticos, como modelos opuestos, que adquieren volumen a través de su evolución. Mediante esta transformación, motivada por la influencia mutua que se ejercen, tanto el personaje de Katherine Hepburn como el de Humphrey Bogart abandonan su rigidez y extremismo inicial para comprenderse (y enamorarse) en un punto intermedio.

La última de las figuras redondas del cine de aventuras que comentaremos será Ben-Hur (Charlton Heston), héroe en una narración de tintes épicos que alcanza contraste, pese a la escasez de rasgos que lo definen, gracias a la incompatibilidad de objetivos propuestos. Por una parte, quiere vengar la injusticia cometida contra él y contra su familia. Por otra, el espíritu cristiano en el que se inicia le habla del amor al prójimo y del perdón a los enemigos.

Surge la diversidad, por tanto, de este conflicto de tono melodramático, relacionado principalmente con la subtrama emocional antes que con la principal. No debemos olvidar que su director, Wyler, articulaba en los melodramas personajes muy perfilados y ambiguos que clasificábamos como redondos. 


\subsection{Personajes planos.}

\subsubsection{Comedia.}

La mayor parte de los protagonistas de comedia se configura como plano. Nos encontramos ante un género con una función de estimulación del humor en el espectador que condicionará la configuración de todos sus componentes narrativos y discursivos. Debido a ello, la figura del personaje subordina su construcción a la función genérica, si bien una parte muy importante de la comicidad de las situaciones y diálogos articulados en el relato procederá de la personalidad del protagonista y de su relación con el resto de tipos.

La frecuente utilización de estereotipos explicaría esta mayoría proporcional de personajes planos. Se basarían en el uso de modelos estereotipados comedias de Howard Hawks como La fiera de mi niña, Bola de fuego y Me siento rejuvenecer. En ellas su protagonista es prácticamente, salvo pequeñas matizaciones, el mismo sujeto, un científico despistado y torpe en un ámbito ajeno a su ocupación, tal como es el referido al trato con la mujer.

En La fiera de mi niña, el profesor David Huxley (Cary Grant) es el paleontólogo opuesto en sus intenciones al personaje interpretado por Katherine Hepburn. Con escasos datos acerca de su vida personal, lineal en cuanto a la compatibilidad de metas que pretende alcanzar, caricaturizado y sin el menor contraste en cuanto a expresión de sus sentimientos, Huxley se percibe como un tipo plano con la única función de constituir el contrapunto cómico al personaje de Hepburn, también de escasa dimensión pero mucho más interesante por su carácter manipulador e imprevisible. El encuentro de ambas personalidades conllevará la creación de situaciones cómicas.

Gary Cooper da vida en Bola de fuego al profesor Potts, esta vez un filólogo sin el menor interés por el mundo femenino, ante el que se muestra tosco, tímido e inexperto. Potts verá alterada su disciplinada y rutinaria existencia por la llegada de una mujer diametralmente opuesta a él (Barbara Stanwyck). Su actuación irá encaminada a evitar los problemas que ella le ocasiona, de modo similar a La fiera de mi niña, con un previsible desarrollo de la trama melodramática, destinada a unirlos.

En la tercera comedia de Hawks señalada, Me siento rejuvenecer, Cary Grant interpreta de nuevo a un científico, Barnaby, si acaso más despistado pero de mayor flexibilidad que el anterior. El centro de atención no se hallará tanto en los 
contratiempos originados por la protagonista femenina como en las reacciones inesperadas que provocará el consumo de un compuesto químico. La droga permitirá mostrar otros registros más variados del sujeto principal de la acción, pero su configuración seguirá siendo unidimensional, uniforme y estereotipada.

Dentro de los tipos lineales de la comedia pueden incluirse aquellos representados de forma continuada por un actor a lo largo de una serie de películas, basadas en la sucesión de gags. Aunque son muchos los ejemplos que podríamos extraer del cine clásico, señalaremos dos de los más populares y recordados.

Uno de ellos es el vagabundo interpretado por Charles Chaplin en Tiempos modernos. Aunque recrea de nuevo el personaje que Chaplin representara en su filmografía muda, la particularidad principal es su inclusión en un contexto generalizado de cine sonoro.

Charlot es un vagabundo del que no conocemos datos acerca de su vida pasada ni personal, caracterizado esquemáticamente por una serie de rasgos y objetivos encauzados en una misma dirección: pícaro, torpe, extravagante, optimista, alegre, ingenuo y bondadoso, no presenta cualidades negativas que ensombrezcan su rol de héroe de la marginalidad. El carácter episódico de sus aventuras le impide al mismo tiempo cualquier transformación que varíe su esencia. La línea argumental constituye un aspecto secundario y el peso de la historia descansa sobre la recreación de escenas cómicas en las se oponen un contexto social institucionalizado con la personalidad anárquica del vagabundo.

El otro caso que comentaremos de caracteres planos en una serie de películas es el formado por los hermanos Marx: Groucho, Chico y Harpo, aun desempeñando distintos roles, con nombres y propiedades diferentes, interpretan los mismos personajes en toda la serie de filmes de los Marx. Identificado cada uno de ellos por unas cualidades propias permanentes en todas las historias, crean estereotipos que mantienen sin variaciones importantes y dentro de una común linealidad. Son pues sujetos planos, unidimensionales, con un comportamiento predecible y objetivos de escasa verosimilitud, al ser inspirados por la lógica del absurdo.

Dentro del género de la comedia puede distinguirse un subgénero en el que adquieren una relevancia privilegiada las relaciones entre la pareja de protagonistas, la comedia romántica. Ésta poseerá no pocos elementos comunes con el melodrama, si bien 
su tono amable y humorístico lo acerca a la comedia antes que a la tragedia más propia del melodrama.

De cualquier forma, los sujetos centrales de la comedia romántica carecen de la complejidad de los tipos más frecuentes en el melodrama. Así, en Sucedió una noche, Claudette Colbert es caracterizada como Ellie, una joven rebelde, adinerada y caprichosa que huye de su padre para encontrarse con su prometido en Nueva York. Su forzado compañero de viaje, Peter Warren (Clark Gable), la evaluará (y la despreciará) por su imagen de joven superficial. Aunque Ellie se manifiesta en contra de esta percepción, no resulta convincente, ya que su actuación no hace sino confirmar la adecuación al estereotipo de niña rica.

El personaje principal, esta vez masculino, de El bazar de las sorpresas, Alfred Kralik (James Stewart) se define desde su coherencia y formalidad. El contraste entre su estricto carácter profesional y su vertiente romántica y culta resultan insuficientes para dotar de volumen al mismo. Alfred no vive grandes conflictos internos, pese a afirmar sentirse confundido y aturdido. La comunicación oral de sus inquietudes, no corroborada en la acción, le resta verosimilitud.

\subsubsection{Musical.}

El personaje del musical se asemeja al de la comedia romántica, no sólo en sus constantes definitorias, sino también en su linealidad y simpleza. Podría constituirse como modelo paradigmático el tipo representado por Gene Kelly en Un día en Nueva York, Un americano en París o Cantando bajo la lluvia. En ellas, Kelly reproduce el mismo estereotipo: el joven alegre, amable, extrovertido y algo ingenuo. Ningún rasgo apunta a un aspecto divergente, por lo que carece de variedad y realismo. Los datos que conocemos acerca de su vida pasada y emocional son muy escasos en las tres historias. El conflicto principal del relato suele proceder de la incompatibilidad de objetivos en $U n$ americano en París y Cantando bajo la lluvia: la consecución de una relación amorosa al tiempo que el logro de un éxito profesional. En todo caso, la capacidad emocional de los sujetos es bastante limitada y esta incertidumbre, que podría acercarlo al melodrama, no es verosímil al quedar supeditada al carácter positivo y optimista del héroe.

\subsubsection{Melodrama.}


Ya propiamente en el melodrama, pueden incorporarse en esta categoría los tipos principales de los dramas analizados dirigidos por Douglas Sirk, Imitación a la vida y Escrito sobre el viento. En Imitación a la vida se plantea una situación inicial de un dramatismo latente, las relaciones entre una familia de raza blanca y otra de raza negra constituidas ambas por una madre y una hija, que terminará por romper su equilibrio en la última parte de la historia. Lana Turner representará a Lora, la madre blanca aspirante a actriz que alcanza el éxito a costa de sacrificar su vida personal y el cuidado de su familia. La contradicción que plantea la simultaneidad de sus objetivos profesionales y privados no creará inestabilidad en el personaje, en todo momento uniforme, sereno, leal y seguro de sí.

El desplazamiento de su familia a un lugar secundario en su escala de valores no le provoca una duda moral que resulte verosímil ni proyectará una sombra de ambigüedad sobre su carácter. En todo momento permanecerá glamorosa en su papel de estrella de éxito, lo que viene a demostrar la escasez de rasgos que la definen.

Escrito sobre el viento pone de nuevo al frente a un personaje vagamente esbozado y construido en torno a un número muy limitado de cualidades que no se contraponen ni le dan variedad o dimensión. Su protagonista, Mitch (Rock Hudson), se configura como un "caballero andante" con la misión de encauzar la vida de los millonarios hermanos para los que trabaja. Compone un tipo heroico, amable pero pasivo y secundario con respecto a los focos dramáticos principales. Mitch se perfila de un modo demasiado perfecto dentro de su rol en el relato. Los sentimientos contradictorios que siente ante los dos hermanos, al hallarse ante la obligación de atenderlos y la necesidad de huida de los mismos, son insuficientes para proporcionarle contraste y volumen.

El tercero de los títulos del melodrama con figuras lineales que comentaremos será el de La señora Miniver. En ésta, Wyler compone un personaje simple y unidimensional, de reducida contradicción en sus metas y rasgos poco variados. La afición de su heroína (Greer Garson) por los sombreros no le basta para añadir diversidad al estereotipo articulado, el del ama de casa inglesa: amable, optimista, luchadora, sumisa, sensible y patriota. La necesidad de creación de sujetos heroicos en tiempos de guerra retratados en su rutina doméstica explicaría la configuración y el éxito del personaje en el contexto histórico de su aparición. 


\subsubsection{Cine negro.}

La frecuente articulación de estereotipos y de constantes de géneros a nivel narrativo y discursivo explica la presencia de personajes planos en roles principales en el cine negro y de intriga. Entre estas composiciones lineales merecen la pena destacar las interpretadas por Humphrey Bogart. En los filmes noir analizados de Hawks (Tener y no tener y El sueño eterno) y Huston (El halcón maltés y Cayo Largo) el actor da vida a personajes similares al Rick de Casablanca, aunque sin su complejidad ni inestabilidad emocional. Los rasgos que los definen apenas poseen variedad, se dirigen en una misma dirección, y la información acerca de su vida personal y pasada es muy limitada, salvo por la comunicación de su ocupación como detectives o profesionales independientes. El modelo bogartiano es duro, realista, desengañado, exiguamente implicado en la acción, indiferente a su entorno, apático, misógino y cínico. Su evolución al compromiso con los hechos desde una actitud heroica suele ser tardía y no logra insuflar veracidad y realismo al estereotipo. Caracterizado como Frank McCloud en Cayo Largo, veterano de guerra desencantado y pasivo a las actividades de la banda de gánsteres, señala que sólo le importa "yo y lo que es mío", añadiendo no pelear "más batallas que las mías". Esta descripción de sí mismo se repite en los demás protagonistas señalados y pesa por encima de las consecuencias que su giro a la lucha activa conllevan en la caracterización de los tipos.

La ausencia de dimensión que subyace en su actuación intenta salvarse a través del discurso oral de otros personajes que intentan definirlo. Así, en El halcón maltés, el cliente para el que trabaja Bogart afirma que éste es "extraordinario", ya que "nunca se sabe lo que va a decir o hacer, pero sí se sabe que sin duda será algo extraordinario". El carácter teleológico mostrado en su acción contradice esta supuesta personalidad imprevisible apreciada por otros actantes de la narración.

Otro actor habitual del cine negro, Glenn Ford, presenta de modo similar una continuidad en los registros interpretados en Gilda, Los sobornados y Deseos humanos, si bien sus personajes muestran mayor contraste que los bogartianos. En Gilda, Ford interpreta el papel de Johnny Farrel, de quien poseemos muy poca información debido a su temperamento hermético, lo que redundará en una construcción en torno a pocos rasgos. Frío, duro, inexpresivo y misógino, ignoramos sus objetivos concretos en la 
historia, careciendo además de cualquier ambigüedad moral. Su nobleza y lealtad lo distinguen de su entorno, con lo cual mantiene su uniformidad y correcta calibración de modo permanente.

El protagonista de Los sobornados, el sargento de policía Dave Bannio, presenta varias facetas que lo complementan y lo contrastan dentro de la unidimensionalidad que lo define. Así, el sujeto principal de la acción es un detective duro, frío e inexpresivo en la línea de Philip Marlowe, bien conocido en la novela y el cine negro. Sin embargo, Bannio también es el padre de familia amante de la comodidad y el afecto hogareño, aspectos estos argumentalmente relevantes en el desarrollo de la historia, al ser su familia el objeto de las venganzas de los antagonistas. En la última parte del filme, el policía se mostrará dudoso ante la posibilidad de hacer efectiva su venganza mediante la muerte del antagonista principal. Podemos pues concluir que Dave Bannio añade un matiz de mayor complejidad en un estereotipo propio del género.

En Deseos humanos, Ford interpreta a Jeff Warren, modelo de buen chico, honrado, trabajador, veterano de guerra, que vuelve a su localidad de origen para el reencuentro con su antiguo way of life. La relación con una femme fatale, que intenta manipularlo e influir en una actuación en un modo opuesto a sus principios, no le crea duda ni inestabilidad. Jeff no evoluciona psicológicamente como personaje y se mantiene fiel a su rol estereotipado. Contribuye a reforzar esta idea la estructura circular del filme, que concluye con planos del tren en que trabaja prácticamente idénticos a los de la secuencia inicial.

\subsubsection{Western.}

Con respecto al western, podemos afirmar que supone posiblemente el género más codificado icónica y narrativamente. Obligado a mantener constantes unas coordenadas geográficas e históricas, los filmes desarrollados en el Oeste americano suelen basarse en la repetición de esquemas argumentales en los que van implícitos los modelos o arquetipos de personajes.

Entre sus protagonistas destacaría por su frecuente aparición el justiciero: como pistolero solitario, dedicado a la ganadería en el pasado, vaga sin otra ocupación que la de encontrar a los responsables de la muerte de un familiar para vengarse. Como objetivo secundario, el forastero establecerá el orden en una comunidad frente a los 
villanos que atentan su estabilidad. Reconocemos este esquema en los sujetos principales (y en los relatos) de La diligencia, Pasión de los fuertes, Winchester 73 o El hombre de Laramie.

En la primera, John Wayne interpreta a Ringo Kid, forajido noble, duro, enérgico, contundente, valiente y seguro de sí, identificado como prototipo de outlaw hero por Casetti y Di Chio (1998: 181). Su meta será vengar la muerte de su padre y su hermano por los antagonistas. A pesar de que su relación con Dallas (Claire Trevor), la prostituta, permite apuntar cierto contraste en su configuración, el personaje conserva su uniformidad y simpleza.

Si el vengador interpretado por Wayne puede señalarse como modelo de outlaw hero, el sheriff Wyatt Earp (Henry Fonda en Pasión de los fuertes) ejemplifica el official hero: de enorme entereza y honestidad, Earp es aquí un sujeto lineal sin otra meta que la de castigar la muerte de su hermano y el robo de su ganado a los responsables del crimen. Sorprende en esta obra hallar secundarios de mayor complejidad psicológica que su protagonista, caso de Doc Hollyday (Victor Mature), decadente y con muy escasa autoestima.

En Winchester 73 y El hombre de Laramie James Stewart interpreta a dos caracteres muy semejantes: forasteros amables, heroicos, aunque con un odio “impropio", según apunta uno de sus ayudantes en la segunda. El origen de su ira se halla en la necesidad de venganza de la muerte de su padre (en Winchester 73) y de su hermano (en El hombre de Laramie). La singularidad de Winchester 73 recae en el planteamiento del tema del cainismo, al identificarse el antagonista con la figura del hermano del protagonista.

En todos estos filmes la mujer juega un papel secundario subordinado al héroe, sin la menor dimensión. Los tipos femeninos adquirirán dimensión y complejidad posteriormente, con la influencia de modelos de personajes procedentes del cine negro, tal y como ocurre en Johnny Guitar o Encubridora.

\subsubsection{Aventuras.}

La presencia habitual de estereotipos en el cine de aventuras y el peplum explicará la frecuente articulación de modelos planos en posiciones jerárquicas superiores, normalmente desarrollando los roles denominados official hero y outlaw 
hero. En la práctica, la distinción entre ambos esquemas de caracterización es compleja, habida cuenta de la fusión de ambos. Así, en Los diez mandamientos identificamos a Moisés (Charlton Heston) como el héroe mesiánico que asume su destino y expresa los valores reconocidos por la colectividad. Sin embargo, no debemos olvidar su carácter rebelde, cercano al outlaw, contra el régimen esclavista del faraón.

Clark Gable puede señalarse en Rebelión a bordo como un outlaw hero prototipo al encarnar un personaje aventurero, independiente y ansioso de libertad que, según Casetti y Di Chio (1998: 181), “expresa las aspiraciones del individuo y las exigencias inéditas de la juventud". La legitimación humanitaria de su revuelta lo acerca a los valores compartidos por la sociedad, por lo que su rol transita entre el outlaw y el official hero. De cualquier forma, ambas construcciones serían muy esquemáticas y no poseerían rasgos ni objetivos contradictorios. La exhibición de la acción pesaría sobre la descripción de caracteres.

\section{Conclusiones.}

Podemos concluir que la categorización del personaje clásico en planos y redondos, a pesar de las limitaciones que implican la evaluación en un sistema binario, permite la extracción de varios rasgos que dotan de coherencia la idea de un personaje construido desde un patrón determinado. Así, en cuanto a la relación entre dimensionalidad y género cinematográfico, el personaje del cine clásico se caracteriza por los siguientes factores:

1) La dimensionalidad del sujeto narrativo se obtiene a través de la transmisión de una amplia cantidad de información, resultado de la exposición del personaje a situaciones de distinta naturaleza. De esta forma se permite el contraste de sus comportamientos, actitudes y reacciones a estímulos dispares.

2) El personaje redondo suele mentir u ocultar datos al resto de sujetos con los que se relaciona. El espectador se percata de ello debido a su conocimiento previo de aquellos aspectos que oculta.

3) El establecimiento en el relato de una relación amorosa con otro personaje posibilita un acercamiento íntimo al protagonista. Es por ello que en el melodrama los tipos redondos abunden por encima de los planos. 
4) El género fílmico condicionará en gran medida la construcción del sujeto de la acción. La influencia de estereotipos y convenciones genéricas determina el hecho de que, en líneas generales, los protagonistas de la comedia, el western y el musical sean planos y lineales. Simultáneamente, los tipos más complejos y contrastados serán los del melodrama. En el cine negro, al igual que en el western, el peso de estereotipos y constantes del género potencian la articulación de estereotipos y arquetipos consecuentemente planos.

5) El protagonista adquiere volumen a causa de la incompatibilidad de objetivos y vías de alcance planteados: la inseguridad e inestabilidad que le provocan conllevará un carácter imprevisible en su actuación que define al personaje redondo.

Podemos concluir que el género cinematográfica al que pertenece el filme condiciona la dimensionalidad del personaje, esto es, su posible clasificación como personaje plano o como personaje redondo. Podemos destacar, en este sentido, la frecuencia con que los personajes protagonistas del melodrama se configuran como personajes de mayor dimensionalidad: el melodrama hace de la vida personal de los protagonistas la trama principal, aspecto que invita a la transmisión de una amplia cantidad de información acerca de aquellos, no solo en lo relativo a la vida profesional, personal y privada, sino, por seguir las categorías de Fiel, también de la vida pasada del personaje.

Reducida la concepción del personaje como un conjunto de rasgos en torno a una entidad física, la cantidad de información sobre éste y la variedad y contraste de dichas informaciones son las que terminan con conferir volumen y credibilidad a los personajes. El melodrama se posiciona, por tanto, como género privilegiado para trazar su eje a partir del desarrollo de la trama en torno a los personajes, razón que invita a la presentación de personajes complejos y redondos.

En el otro extremo, nos encontraríamos con los géneros que hacen del desarrollo de la acción física su motivo principal. Aunque es posible, como hemos visto, localizar personajes redondos en la comedia, el western o el cine de aventuras, la focalización prioritaria de la representación de la actividad y de la acción física que habitualmente hacen estos géneros margina un desarrollo más profundo del personaje.

Selbo (2015) argumenta la polarización de los géneros en dos extremos, entre los que podrían ubicarse el resto: drama y comedia. De forma paralela, podríamos hacer 
identificar la dicotomía personaje redondo/personaje plano con su pertenencia al drama o la comedia. Como toda categorización, resulta inevitablemente reduccionista y simplificador de la complejidad del estudio y de la caracterización del personaje, pero la propia conceptualización del género cinematográfico es por fuerza reduccionista, tanto como la propia división en dos modelos de personajes según su dimensionalidad.

La asociación de unos personajes con los géneros en los que se inscriben llega a hacer posible la definición de género a partir de su presencia en la historia. Sin embargo, por otra parte, se espera una caracterización del sujeto en función de su incursión en un filme de un género concreto, como parte de sus convenciones específicas. Entraría en juego, en este caso, una cuestión que no hemos abordado aquí dada la naturaleza del análisis textual realizado: aquellos elementos extradiscursivos conocidos por los espectadores que influyen y condicionan la configuración del personaje. Proponemos así una futura ampliación de este trabajo a través del análisis extradiscursivo centrado en la interpretación de la audiencia a la hora de definir tanto los géneros como las expectativas que generarían en cuanto a construcción de personajes.

\section{Referencias bibliográficas.}

Allen, R. \& Gomery, D. (1995): Teoría y práctica de la historia del cine. Barcelona: Paidós.

Alonso De Santos, J.L. (1998): La escritura dramática. Madrid: Castalia.

Altman, R. (1999): Los géneros cinematográficos. Barcelona: Paidós.

Bal, M. (1985): Teoría de la narrativa (Una introducción a la narratología). Madrid: Cátedra.

Bobes, M.C. (1990): El personaje novelesco: cómo es, cómo se construye, en Mayoral, M. (Ed.) .El personaje novelesco. Madrid: Cátedra.

Bordwell, D., Staigar, J. \& Thompson, K. (1997): El cine clásico de Hollywood. Barcelona: Paidós.

Casetti, F. \& Di Chio, F. (1998): Cómo analizar un film. Barcelona: Paidós.

Comparato, D. (1992): De la creación al guión. Madrid: Instituto Oficial de Radio y Televisión RTVE. 
Corbetta, P. (2007). Metodología y técnicas de investigación social. Madrid: Mc Graw Hill.

Coursodon, J.P. (1996): La evolución de los géneros, en VV.AA: Historia general del cine. Volumen VIII. Madrid: Cátedra.

Crespo Gámez, C. (2001): Géneros cinematográficos. Sevilla: Universidad de Sevilla (trabajo de investigación).

Currie, H. (1976): La visión esquemática de Joseph Von Sternberg: La Venus rubia, en Staples, D. Antología del cine norteamericano. Buenos Aires: Marymar.

Chatman, S. (1990): Historia y discurso. La estructura narrativa en la novela y el cine. Madrid: Taurus.

Durán Manso, V. (2017): Los rasgos melodramáticos de Tennessee Williams en Pedro Almodóvar: estudio de personajes de La ley del deseo, Tacones lejanos y La flor de mi secreto. Vivat Academia Revista de Comunicación, 138; 96-119 (http://dx.doi.org/10.15178/va.2017.138.96-119) (05-09-17).

Dyer, R. (2001): Las estrellas cinematográficas. Barcelona: Paidós.

Field, S. (1995): El libro del guión. Madrid: Plot.

Forster, E.M. (1983): Aspectos de la novela. Madrid: Debate.

García Jiménez, J. (1993): Narrativa audiovisual. Madrid: Cátedra.

Greimas, A.J. (1971): Semántica estructural. Madrid: Gredos.

Gubern, R. (1989): Historia del cine. Barcelona: Lumen.

Onaindia, M. (1996): El guión clásico de Hollywood. Barcelona: Paidós.

Parker, P. (1998): The art and science of screenwriting. Exter: Intellect.

Pérez-Rufí, J.P. (2016): Metodología de análisis del personaje cinematográfico: Una propuesta desde la narrativa fílmica. Razón y palabra, 20 (4-95); 534-552 (http://www.revistarazonypalabra.org/index.php/ryp/article/view/685/pdf) (05-09-17). Romaguera i Ramió, J. (1999): El lenguaje cinematográfico. Gramática, géneros, estilos $y$ materiales. Madrid: Ediciones de la Torre.

Seger, L. (2000): Cómo crear personajes inolvidables. Barcelona: Paidós.

Selbo, J. (2015): Film Genre for the Screewriter. New York \& London: Routledge.

Vale, E. (1989): Técnicas del guión para cine y televisión. Barcelona: Gedisa.

Villanueva, D. (1989): El comentario de textos narrativos: la novela. Gijón: Júcar. 